\title{
Periodic growth and growth cessations in the federally endangered freshwater mussel Cumberlandian combshell using a hierarchical Bayesian approach
}

\author{
Dan Hua ${ }^{1,2, *}$, Yan Jiao ${ }^{1}$, Richard Neves ${ }^{1}$, Jess Jones $^{1,2,3}$ \\ ${ }^{1}$ Department of Fish and Wildlife Conservation, College of Natural Resources, Virginia Polytechnic Institute and State University, \\ Blacksburg, VA 24061, USA \\ ${ }^{2}$ Freshwater Mollusk Conservation Center, Virginia Polytechnic Institute and State University, Blacksburg, VA 24061, USA \\ ${ }^{3}$ US Fish and Wildlife Service, Department of Fish and Wildlife Conservation, Virginia Polytechnic Institute and State University, \\ Blacksburg, VA 24061, USA
}

\begin{abstract}
Understanding and monitoring life history traits is often important in endangered species conservation. Populations of the endangered mussel Cumberlandian combshell Epioblasma brevidens have continued to decline in the Powell River, USA. Understanding and modeling mussel growth is critical for effective reintroduction of this endangered species. In this study, 2 yr old E. brevidens that were produced in our laboratory were released to the Powell River in 2009 to augment this declining population. A mark-recapture monitoring approach using passive integrated transponder (PIT) tags was used to assess the survival and growth of the released mussels. Hierarchical Bayesian growth models incorporating individual growth variations, periodic growth and growth cessations, along with multiple release occasions were developed and compared to the classic von Bertalanffy growth model. Our results showed that the hierarchical model that incorporated individual growth variation gave the best estimates of model parameters, yielding the lowest deviance information criterion value. Mussels exhibited different growth rates $(K)$, including $0.015,0.026,0.110$ and $0.050\left(\mathrm{mo}^{-1}\right)$, corresponding to the duration of laboratory culture (ages 2, 3 and $4 \mathrm{yr}$ old) and a growth cessation (GC) for $5.98 \mathrm{mo}$, respectively. The other parameters of asymptotic length $\left(L_{\infty}\right)$ and age at zero length $\left(t_{0}\right)$ were $51.36 \mathrm{~mm}$ and $-0.648 \mathrm{mo}$. The flexible structure of Bayesian hierarchical models allowed us to examine growth characteristics of $E$. brevidens in a changing environment to better understand the details of its growth and lifespan, thus providing useful data for conservation management.
\end{abstract}

KEY WORDS: Freshwater mussel $\cdot$ Cumberlandian combshell $\cdot$ Epioblasma brevidens $\cdot$ Growth rate · Asymptotic length · Growth cessation · Periodic growth · von Bertalanffy growth model · Bayesian hierarchical model

\section{INTRODUCTION}

The freshwater mussel fauna (Unionoida) of North America contains the highest diversity in the world, with 281 species and 16 subspecies (Williams et al. 1993, Neves 2008, Graf 2013); however, it is the most

${ }^{*}$ Corresponding author: huad@vt.edu imperiled group of freshwater animals in North America (Ricciardi \& Rasmussen 1999, Haag 2012). At least 29 species have gone extinct over the last $100 \mathrm{yr}$ (Haag \& Williams 2014); 75 species are currently listed in the USA as federally endangered, and an additional 13 species are threatened (Williams et

() The authors 2016. Open Access under Creative Commons by Attribution Licence. Use, distribution and reproduction are unrestricted. Authors and original publication must be credited. 
al. 1993). To reduce the risk of species extinction, various conservation management strategies have been implemented over the last $30 \mathrm{yr}$, including reintroduction and augmentation of populations with hatchery propagated mussels (National Native Mussel Conservation Committee 1998, Hua et al. 2013) and translocation of adults to sites and populations in need of restoration (Cope \& Waller 1995, Hamilton et al. 1997).

The Powell River, located in southwestern Virginia and northeastern Tennessee of the eastern USA, is part of the upper Tennessee River watershed. It supports a unique assemblage of $>35$ extant mussel species, 13 of which are listed as endangered species in the United States Endangered Species Act (ESA) of 1973. However, quantitative mussel surveys conducted in the Powell River from 1979 to 2004 documented a $63 \%$ decline in mean mussel density (mussels $\mathrm{m}^{-2}$ ) (Ahlstedt et al. 2005). A more recent quantitative survey conducted from 2008 to 2010 revealed that mussel populations have continued to decline in the river, including the Cumberlandian combshell Epioblasma brevidens (Johnson et al. 2011). This species is listed as endangered under the ESA and is also considered globally Critically Endangered on the International Union for Conservation of Nature (IUCN) Red List. The recovery plan for $E$. brevidens recommends reintroduction of propagated mussels into previously occupied habitats (USFWS 2004). Hence, an effective approach for monitoring populations of this and other reintroduced mussel species is essential in order to evaluate population viability, shell and body growth, life history traits, habitat suitability, and the success of conservation efforts.

Body size, growth, and survival are important life history traits that have been monitored and analyzed by fisheries scientists for decades (Hilborn \& Walters 1992, Haddon 2001). In fisheries, the most commonly used model to describe fish growth was developed by von Bertalanffy (1938), and this has since been applied to the analysis of growth in freshwater mussels (Neves \& Moyer 1988, Hastie et al. 2000, Miguel et al. 2004, Jiao et al. 2008, Haag \& Rypel 2011, Jones \& Neves 2011). The von Bertalanffy growth model (VBGM) is expressed mathematically as a 3-parameter equation, $L_{t}=L_{\infty}\left[1-\mathrm{e}^{-K\left(t-t_{0}\right)}\right]$, where $L_{\infty}$ is the theoretical maximum body length, $K$ is the growth rate coefficient, and $t_{0}$ is the hypothetical age at zero length. The parameters in the equation are typically analyzed by combining data for all individuals in a population. Hence, the standard VBGM model assumes homogeneity of individuals in a population dynamic assessment, which can introduce bias into model construction and parameter estimation (Pledger et al. 2003). A result of introducing bias is that estimates of model parameters are poorly characterized (Conner \& White 1999, Cam et al. 2002). For example, growth rates of individuals can vary substantially with temperature, food availability, population density, and habitat location (Krohn et al. 1997, Swain et al. 2003, Kimura 2008, Jiao et al. 2010). Hence, growth models that incorporate individual variations are considered more realistic and appropriate to describe the growth pattern of a population (James 1991, Smith et al. 1997, Alós et al. 2010, Tang et al. 2014). These models incorporate residual variance into the modeling process, so growth heterogeneity of individuals can be assessed to better understand the species' population biology (Pledger et al. 2003). A Bayesian approach using Markov Chain Monte Carlo (MCMC) algorithms is considered the most efficient mathematical framework to incorporate and reduce model uncertainty (Wade 2000, Gimenez 2008).

The growth of aquatic animals often exhibits strong seasonal oscillations, mainly due to fluctuations in temperature, food supply (Shul'man 1974), body reserves (Bacon et al. 2005), and even social behavior (Alanara et al. 2001). Freshwater mussels experience growth cessation (GC) during the winter months in most North American geographic locations (Downing et al. 1992, Downing \& Downing 1993, Anthony et al. 2001). Hence, the VBGM has been discussed and modified to allow for seasonal oscillations during specific growth periods. The seasonal growth model was originally proposed by Ursin (1963) and has been modified by including a sine-wave function into the traditional VBGM to allow for seasonal oscillations (Pitcher \& MacDonald 1973, Cloern \& Nichols 1978, Pauly \& Gaschultz 1979, Somers 1988, Hoenig \& Hanumara 1990, Allison 1994). However, earlier versions of the seasonal oscillating models may not have been well suited for characterizing mussel growth (Pauly et al. 1992). Further, another challenging issue in freshwater mussel conservation management is how to evaluate growth rates of populations that are exposed to a suite of environmental stressors, such as pollution and climate change, because changes in environmental conditions can cause variations in growth rates of successive cohorts or stocks of same species (Rizvi et al. 2012). Overall, estimates of growth parameters ( $K$ and $L_{\infty}$ ) have not incorporated individual variations, seasonal variations, or growth cessations for freshwater mussels, primarily due to an absence of reliable data and advanced demographic modeling techniques. 
Effective conservation and restoration management of endangered mussels will require a thorough understanding of the species' life history traits and population dynamics. Thus, the purpose of our study was to develop a new model incorporating individual variations and seasonal variations with GC to model the growth of $E$. brevidens. We also demonstrate applications of stochastic analyses with modifiable models through a Bayesian approach to meet the various realistic environmental circumstances.

\section{MATERIALS AND METHODS}

\section{Laboratory propagation and tagging of mussels}

Juveniles of Epioblasma brevidens were propagated and cultured at the Freshwater Mollusk Conservation Center (FMCC) of the Department of Fish and Wildlife Conservation, Virginia Tech, Blacksburg, VA, USA. All juveniles were from 1 propagation effort in 2007 . Juveniles were reared in 2 culture systems utilizing pond water, one of which was an open-water recirculating system and the other one was a closed recirculating aquaculture system. In winter, a mixed algal diet (Shellfish Diet 1800 and Nanno 3600; Reed Mariculture) was used as supplemental food for juveniles, which were fed at a mean concentration of 35000 cells ml ${ }^{-1}$. Newly transformed juvenile mussels were cultured in tanks with fine sediment $(<200 \mu \mathrm{m})$ at a depth of 1 to $2 \mathrm{~mm}$, and were moved to a limestone gravel substrate ( 2 to 5 $\mathrm{mm}$ ) for grow-out when they reached a length of $3 \mathrm{~mm}$. Juvenile size (length) was measured and counted on 12 sampling occasions during the 2 yr culture period. Survival rates were calculated as percent of the number collected in the previous sampling period.

Once juvenile mussels were $>20 \mathrm{~mm}$ long, they were tagged using Bulk PIT tags (TX1411SST; Biomark) to ensure high recapture rates of each individual. Glue-on shellfish tags (Type FPN; Hallprint) were also attached to the other valve. Double tagging on both valves of the mussels secured the identification information during the monitoring process. Tagged juvenile mussels were released at Brooks Bridge $\left(36^{\circ} 32^{\prime}\right.$ 05.5644" N, 8326'30.3432"W), Powell River, Tennessee, USA, on multiple occasions, including 1 July 2009, 26 August
2009, 7 October 2009, 25 June 2010, and 11 October 2010 (Fig. 1). They were then relocated using the PIT tag detector for measurement of length, then returned to the release site. A total of 8 mark-recapture sampling events were implemented during this study.

\section{Water quality measurement}

Water temperature was determined using a YSI multi-probe water quality meter (model 55/12 FT). Organic matter content was measured through ash free dry weight (AFDW) following standard methods for the examination of water and wastewater (Method 10300 C, D; APHA 1998).

\section{Models and equations}

Two new growth models were developed and the VBGM was applied in this study with the following assumptions: (1) labeled juvenile mussels retained their tags throughout the study, and PIT tags were detectable without negative influence on their survival $_{\text {( }}$ (2) variation in mussel length followed a certain random distribution; and (3) sampling protocol and study area were constant.

In the formulation for Model 1, the VBGM was applied as:

$$
L_{t}=L_{\infty}\left[1-\mathrm{e}^{-K\left(t-t_{0}\right)}\right]
$$

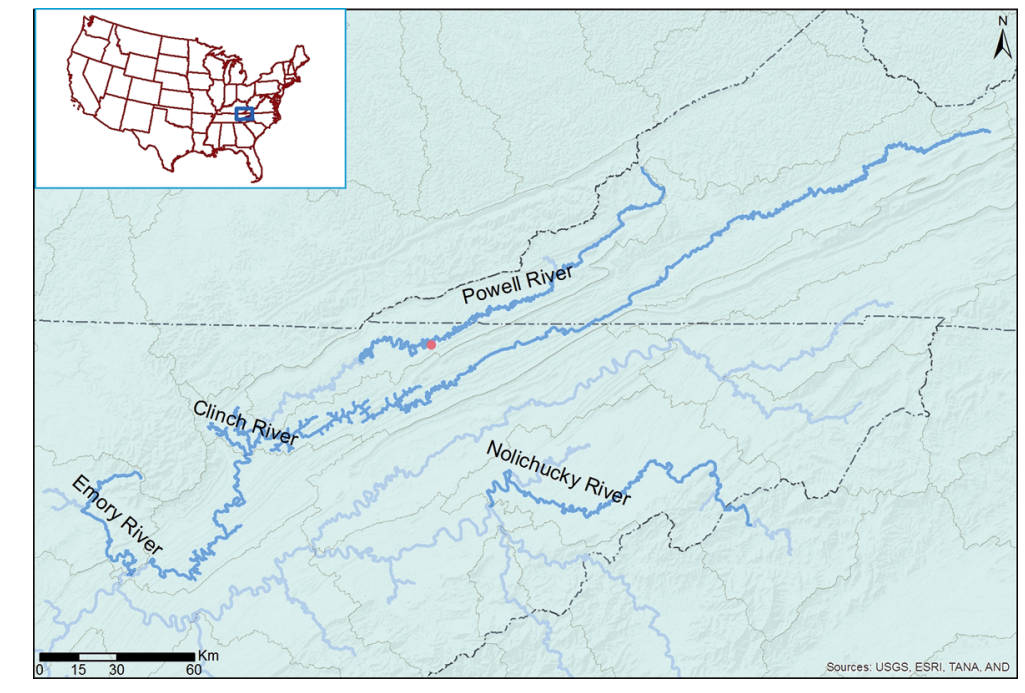

Fig. 1. Release location (red dot) of juvenile mussels of Epioblasma brevidens at Brooks Bridge (36 $\left.32^{\prime} 05.5644^{\prime \prime} \mathrm{N}, 83^{\circ} 26^{\prime} 30.3432^{\prime \prime} \mathrm{W}\right)$ in the Powell River, Tennessee, USA 
where $L_{t}$ represents the length of the mussel at time $t$ (months), $L_{\infty}$ (asymptotic length) denotes the theoretical average maximum body length, $K$ represents growth rate coefficient that defines growth rate toward the maximum, and $t_{0}$ represents the hypothetical age when mussels were at zero length.

Applying the Bayesian approach to Model 1, a traditional and non-hierarchical VBGM was constructed as:

$$
E\left(L_{j}\right)=L_{\infty}\left[1-\mathrm{e}^{-K\left(t_{j}-t_{0}\right)}\right]
$$

where $j$ represents the capture occasion (or sampling measurement, $j=0,1,2 \ldots 8 ; j=0$ denotes the time of mussel release); $E\left(L_{j}\right)$ denotes the expected mussel length on the $j^{\text {th }}$ capture occasion; $t_{j}$ represents the mussel age (months) on the $j^{\text {th }}$ occasion; $L_{\infty} K$ and $t_{0}$ are corresponding parameters to those described above, and their prior probability distributions were $U(45,100), U(0,1)$ and $U(-2,2)$ separately. $L_{j}$ was assumed to follow a normal distribution, $N\left(E\left(L_{j}\right), \sigma_{L}^{2}\right)$, and prior of $\sigma_{L}^{2}$ was assumed to be $U(0,400)$.

Since released mussels exhibited uneven or abnormal growth with a potential non-growth season and different annual growth rates during the sampling observations (see Fig. 3), 2 new models were developed based on the above preliminary diagnostics to explore the growth of $E$. brevidens for the purposes of propagation and conservation. The newly developed models were then compared with the commonly used VBGM to test their goodness-of-fit.

The formulation for Model 2 included 2 scenarios. (1) Juvenile growth during the culture period in laboratory was analyzed using the VBGM to evaluate the parameters of $K, t_{0}$ and $L_{\infty}$ and (2) Model 2 was reconstructed from the VBGM based on the timebased length increment of the tagged mussels (Fabens 1965, Jiao et al. 2010) after they were released to the river:

$$
E\left(L_{t}\right)=L_{\infty}\left[1-\mathrm{e}^{-K\left(t-t_{0}\right)}\right]
$$

before mussel release (Model 2-1),

$$
\begin{gathered}
E\left(L_{t+\Delta t}\right)=L_{t}+\left(L_{\infty}-L_{t}\right)\left(1-\mathrm{e}^{-K \Delta t}\right) \\
\text { after mussel release (Model 2-2), }
\end{gathered}
$$

where $L_{t}$ represents mussel length at time $t$ (months); $L_{t+\Delta t}$ denotes mussel length at time $t+\Delta t_{i} L_{\infty}, K$, and $t_{0}$ are the same as in Eqs. (1) \& (2). $\Delta t$ is the duration between $t+\Delta t$ and $t$. The other parameters are the same as Eq. (1).

Applying the Bayesian approach, Model 2-2 incorporated variations in annual growth rates and considered the non-growth seasons, while Model 2-1 did not because all the mussels were cultured in the lab environment during this time period. Model 2, the Bayesian non-hierarchical model was constructed as:

$$
\begin{gathered}
E\left(L_{j}\right)=L_{\infty}\left[1-\mathrm{e}^{-K_{1}\left(t_{j}-t_{0}\right)}\right] \text { if } t_{j}<\text { the age at release, } \\
E\left(L_{j}\right)=L_{j-1}+\left(L_{\infty}-L_{j-1}\right)\left[1-\mathrm{e}^{-K_{g}\left(\Delta t_{j-1}-\mathrm{GC}\right)}\right] \\
\text { if } \Delta t_{j-1}>\mathrm{GC} \text { after } 1 \text { November } \\
E\left(L_{j}\right)=L_{j-1} \text { if } \Delta t_{j-1}<\mathrm{GC} \text { after } 1 \text { November }
\end{gathered}
$$

where $j$ represents the $j^{\text {th }}$ capture occasion; $E\left(L_{j}\right)$ represents the expected mussel length at the $j^{\text {th }}$ capture occasion; and $L_{j}$ denotes the mussel length on the $j^{\text {th }}$ occasion, and follows a normal distribution with mean $E\left(L_{j}\right)$ and variance $\sigma_{L}^{2}$. $K_{1}$ denotes the growth rate of juvenile mussels cultured in laboratory; $K_{g}$ denotes the growth rates of released mussels at various stages $(g=2,3,4$ represents the time in 2009, 2010 and 2011 along with the ages of mussels, 2, 3 and $4 \mathrm{yr}$, respectively); $\Delta t_{j-1}$ denotes the duration (months) between the recapture occasion of $(j-1)^{\text {th }}$ and $j^{\text {th }} ;$ GC is the annual growth cessation (months), which begins on 1 November based on empirical growth data at the release site. Mussels were released on multiple occasions; therefore, this model was constructed on the combinations of separated analyses of each release occasion to minimize uncertainties. Priors of $L_{\infty}, K, t_{0}$ and $\sigma_{L}{ }^{2}$ were assumed to be the same as in Model 1, and the prior of $\mathrm{GC}$ here was $U(2,6)$.

Model 3 was generated from Model 2, additionally incorporating individual variations of released mussels since each mussel had an identical tag number at the release. Model 3, the Bayesian hierarchical model was constructed as:

$$
\begin{gathered}
E\left(L_{j}\right)=L_{\infty}\left[1-\mathrm{e}^{-K_{1}\left(t_{j}-t_{0}\right)}\right] \text { if } t_{j}<\text { the age at release } \\
E\left(L_{i, j}\right)=L_{i, j-1}+\left(L_{\infty, i}-L_{i, j-1}\right)\left[1-\mathrm{e}^{-K_{i, g}\left(\Delta t_{j-1}-\mathrm{GC}_{i}\right)}\right] \\
\text { if } \Delta t_{j-1}>\mathrm{GC}_{i} \text { after } 1 \text { November } \\
E\left(L_{i, j}\right)=L_{i, j-1} \text { if } \Delta t_{j-1}<\mathrm{GC}_{i} \text { after } 1 \text { November } \\
L_{\infty, i} \sim N\left(\bar{L}_{\infty} \sigma_{L_{\infty}}^{2}\right) I(45,100) \\
\bar{L}_{\infty} \sim U(45,90) \\
\sigma_{L_{\infty}}^{2} \sim U(0,400) \\
K_{i, g} \sim N\left(\bar{K}_{g}, \sigma_{K_{g}}^{2}\right) I(0,1) \\
\bar{K}_{g} \sim U(0.001,0.3) \\
\sigma_{K_{g}}^{2} \sim U(0.0001,0.1) \\
\mathrm{GC}_{i} \sim N\left(T, \sigma_{t}^{2}\right) I(2,6) \\
T \sim U(2,6) \\
\sigma_{t}^{2} \sim U(0.0001,5)
\end{gathered}
$$

where $i$ represents the $i^{\text {th }}$ individual $i j$ represents capture occasions; $E\left(L_{i, j}\right)$ denotes the expected 
length of the $i^{\text {th }}$ mussel on the $j^{\text {th }}$ occasion; $K_{1}$ denotes the growth rate of juvenile mussels cultured in the laboratory; $L_{\infty, i}$ and $K_{i, g}$ are corresponding parameters of mussel length and growth rate coefficient of individual $i$. They are assumed to follow normal distributions, described as $N\left(\bar{L}_{\infty}, \sigma_{L_{\infty}}^{2}\right)$ and $\left(\bar{K}_{g}, \sigma_{K_{g}}^{2}\right)$, in which $\bar{L}_{\infty, i}$ and $\bar{K}_{g}$ (mean values of each parameter) are assumed to follow uniform distributions with the variance of $\sigma_{L_{\infty}}^{2}$ and $\sigma_{K_{g}^{\prime}}^{2}$ respectively. GC is assumed to follow normal distribution with mean $T$ and variance $\sigma_{t}^{2}$, in which $T$ is further assumed to follow a uniform distribution. $I$ denotes the limited boundary of the parameter distribution; the other parameters are the same as those in Model 2. Priors for hyperparameters were listed in Eq. (10) to help with clarification of the hierarchical model.

\section{Bayesian theorem and WinBUGS program}

The posterior distribution of the parameters was estimated using a Bayesian approach with the software WinBUGS version 14 (MRC Biostatistics Unit and Imperial College School of Medicine; Spiegelhalter et al. 1996). Three Markov chains were used in the analysis and Gelman Rubin statistics were used to determine the convergence of the posterior distribution (Spiegelhalter et al. 2004, Jiao et al. 2008, 2009). The burn-in iteration (50000) and thinning interval (5) were determined based on the convergence criteria following Jiao et al. (2008). For each chain, the first $50000 \times 5$ runs were discarded, and another $5000 \times 5$ runs were continued and saved. The Bayesian inference was generated from samples taken as random draws from the posterior distribution after the 3 chains reached convergence (i.e. 5000 of each chain were saved for the posterior distributions of the parameters in this case). The WinBUGS codes are available upon request or online at www.yanjiao.fishwild.vt.edu.

\section{Goodness-of-fit}

Deviance information criterion (DIC) was applied to the Bayesian model selection using MCMC simulation to determine posterior distributions of each model (Spiegelhalter et al. 2002). The DIC was used in this study to determine goodness-of-fit for the Bayesian models, and formulated as:

$$
\begin{gathered}
\mathrm{DIC}=2 \bar{D}(\theta)-\hat{D}(\theta) \text { or } \bar{D}(\theta)+P_{D} \\
P_{D}=\bar{D}(\theta)-\hat{D}(\theta)
\end{gathered}
$$

where $D$ is deviance used to measure predicted goodness-of-fit for all 3 models, $P_{D}$ is the effective number of parameters in the Bayesian model, $\bar{D}$ is the posterior mean of the deviance, and $\hat{D}$ is the deviance of the posterior mean. $\theta$ represents the stochastic nodes upon which the distribution of observation depends. Models were evaluated using rules of thumb (Burnham \& Anderson 1998, Spiegelhalter et al. 2002), where a model with the smallest DIC value was defined as the best model; models within 1 to 2 DIC units of the 'best' model were also considered the best model, and models within 3 to 7 DIC units of the 'best' model were considered deficiently performed.

\section{RESULTS}

Juveniles of Epioblasma brevidens were successfully propagated and cultured to taggable sizes $(>20 \mathrm{~mm})$ for release to the Powell River in accordance with the species recovery plan (USFWS 2004). In total, 8310 juvenile mussels were produced and cultured at FMCC. As expected, juveniles grew faster in summer and slower in winter during the culture period in the laboratory, and experienced high mortality from Day 1 to Day 60, but survival rates stabilized after 2 mo (Fig. 2). Juveniles had a survival rate of $10 \%$ during the first month, $27 \%$ during the second month, and $100 \%$ thereafter on each sampling occasion.

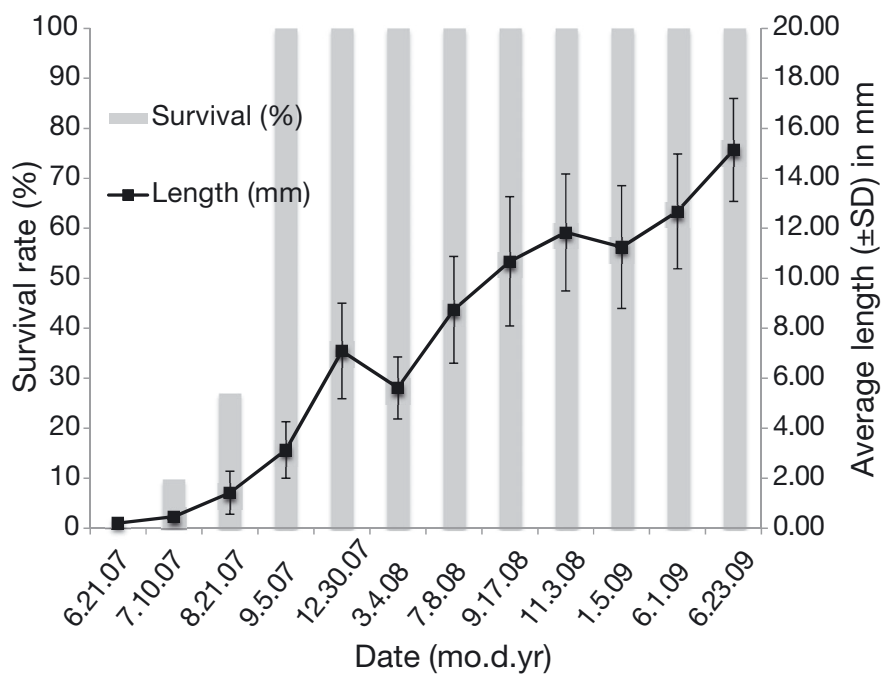

Fig. 2. Survival rate and growth of juveniles of Epioblasma brevidens from Day 1 to taggable size, June 2007 to June 2009 


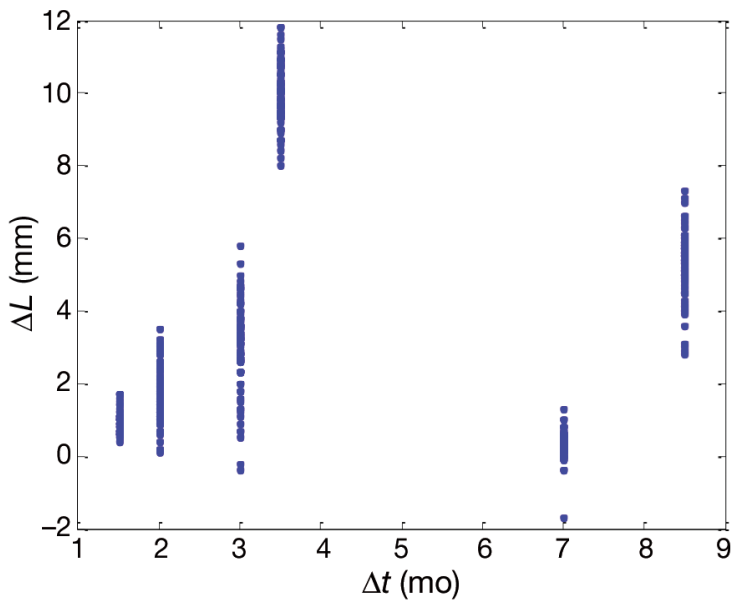

Fig. 3. Relative growth (incremental length $\Delta L$ sample duration $\Delta t$ ) of individual mussels at each recapture occasion

The increments of individual mussel length (Fig. 3) and their distribution (Fig. 4) of the adjacent sampling interval on each observation occasion exhibited fluctuation in the growth curve, with an annual GC or even negative growth starting from about 1 November to 1 May after mussels were released into the Powell River.
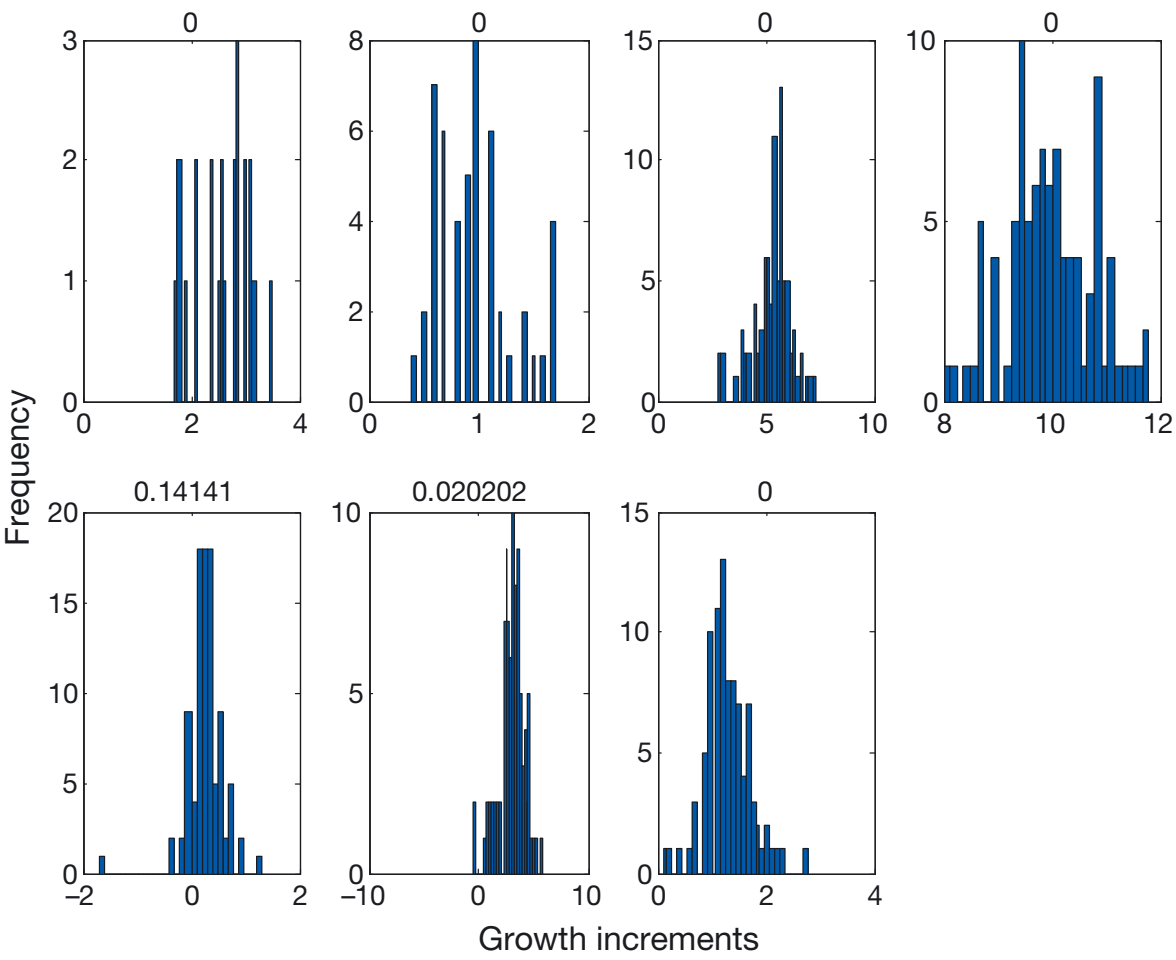

Fig. 4. Distribution of relative growth of individual mussels on each capture occasion on 26 August 2009, 7 October 2009, 25 June 2010, 11 October 2010, 10 May 2011, 17 August 2011, and 12 October 2011 (from top left to right and bottom left to right). Percentage of negative growth is shown above each histogram
Results from Model 1 showed that $K, L_{\infty}$ and $t_{0}$ of released mussels were $0.009 \mathrm{mo}^{-1}, 99.18 \mathrm{~mm}$ and $1.94 \mathrm{mo}$, respectively (Table 1 ). Model 2 provided 4 different growth rates of $0.015,0.031,0.105$ and $0.050 \mathrm{mo}^{-1}$, respectively, which represented variations in mussel growth at 4 different stages. Obviously, 3 yr old mussels had the most rapid growth, followed by 4 yr old and 2 yr old individuals. Juvenile mussels grew slowly during their culture time in the laboratory and during the non-growth winter season, which lasted 5.975 mo. Further, $L_{\infty}$ and $t_{0}$ for E. brevidens estimated in Model 2 were $53.31 \mathrm{~mm}$ and -0.649 , respectively (Table 1 ). Mean growth rates of mussels at the 4 stages estimated from the hierarchical model were $0.0150 .026,0.110$ and $0.050 \mathrm{mo}^{-1}$, respectively. The parameters of $\bar{L}_{\infty}, T$ and $t_{0}$ agreed with the results from Model 2 as well, at $51.36 \mathrm{~mm}$, $5.98 \mathrm{mo}$ and $-0.648 \mathrm{mo}$, respectively (Table 1 ). The goodness-of-fit of each model can be compared by both the DIC values and the plots of model fit (Table 1, Figs. 5-7). Model 1 (Fig. 5) had the lowest fit compared to Model 2 (Fig. 6) and Model 3 (Fig. 7), indicating that the classic VBGM is less suitable to predict mussel growth without incorporating nongrowth seasons. In this study, juveniles of E. brevidens were released on multiple occasions; hence, cohorts released on the same occasion were grouped together for analyses, as indicated by the multiple lines presented in Figs. 6 \& 7. Juveniles cultured in the laboratory were considered as 1 cohort, denoted by the light blue line in Model 2 (Fig. 6). The other parallel lines showed estimated average length of the mussel groups released during multiple time periods throughout the sampling occasions. Model 3 is the hierarchical model that incorporated individual variations. The multiple lines during the juvenile culture period in the laboratory indicated variations among the release groups in this model (Fig. 7). However, individual variations in length among mussels cultured in the laboratory or released to the river as cohort were not significant.

The results of our study indicated that the DIC values of the 3 models were substantially differ- 
Table 1. Estimated parameters of 3 models and their deviance information criterion (DIC) values. $L_{\infty}$ : theoretical average maximum body length; $K$ : growth rate coefficient that defines growth rate toward the maximum; $t_{0}$ : hypothetical age when mussels were at 0 length. $K_{g}$ : growth rates of released mussels at various stages $(g=1$ represents the time in the laboratory; represents the time in 2009, 2010 and 2011 along with the mussel ages at 2, 3 and $4 \mathrm{yr}$, respectively); $T$ : non-growth time (started on 1 November). $L_{\infty}$ and $K_{g}$ in Model 3 represent the corresponding parameters of mussel length and growth rate coefficient of individuals following normal distributions of mean and variances $\left(\bar{L}_{\infty}, \sigma_{L_{\infty}}^{2}\right)$ and $\left(\bar{K}_{g}, \sigma_{K_{g}^{2}}^{2}\right)$

\begin{tabular}{|c|c|c|c|c|c|c|}
\hline Model & DIC & Parameter & r Mean & SD & \multicolumn{2}{|c|}{$95 \% \mathrm{CI}$} \\
\hline \multirow[t]{3}{*}{ Model 1} & 3292.8 & $L_{\infty}(\mathrm{mm})$ & 99.180 & 0.806 & 97.080 & 99.980 \\
\hline & & $K\left(\mathrm{mo}^{-1}\right)$ & 0.009 & $1.068 \times 10^{-4}$ & 0.009 & 0.010 \\
\hline & & $t_{0}(\mathrm{mo})$ & 1.939 & 0.061 & 1.773 & 1.998 \\
\hline \multirow[t]{7}{*}{ Model 2} & 2546.0 & $L_{\infty}(\mathrm{mm})$ & 53.310 & 6.262 & 45.940 & 68.380 \\
\hline & & $K_{1}\left(\mathrm{mo}^{-1}\right)$ & 0.015 & 0.002 & 0.010 & 0.018 \\
\hline & & $K_{2}\left(\mathrm{mo}^{-1}\right)$ & 0.031 & 0.005 & 0.021 & 0.039 \\
\hline & & $K_{3}\left(\mathrm{mo}^{-1}\right)$ & 0.105 & 0.023 & 0.062 & 0.142 \\
\hline & & $K_{4}\left(\mathrm{mo}^{-1}\right)$ & 0.050 & 0.017 & 0.022 & 0.083 \\
\hline & & GC (mo) & 5.975 & 0.025 & 5.908 & 5.999 \\
\hline & & $t_{0}(\mathrm{mo})$ & -0.649 & 0.977 & -1.949 & 1.566 \\
\hline \multirow{10}{*}{ Model 3} & 1683.0 & $\bar{L}_{\infty}(\mathrm{mm})$ & 51.360 & 0.993 & 49.740 & 53.220 \\
\hline & & $\sigma_{L_{\infty}}^{2}$ & 2.410 & 0.204 & 2.041 & 2.838 \\
\hline & & $\bar{K}_{1}^{\infty}\left(\mathrm{mo}^{-1}\right)$ & 0.015 & $5.758 \times 10^{-4}$ & 0.014 & 0.017 \\
\hline & & $\bar{K}_{2}\left(\mathrm{mo}^{-1}\right)$ & 0.026 & 0.002 & 0.022 & 0.029 \\
\hline & & $\bar{K}_{3}\left(\mathrm{mo}^{-1}\right)$ & 0.110 & 0.005 & 0.102 & 0.119 \\
\hline & & $\bar{K}_{4}\left(\mathrm{mo}^{-1}\right)$ & 0.050 & 0.004 & 0.044 & 0.057 \\
\hline & & $\sigma_{K_{g}} \quad 8$ & $8.299 \times 10^{-2}$ & $1.471 \times 10^{-4}$ & $5.416 \times 10^{-4}$ & 40.001 \\
\hline & & $T(\mathrm{mo})$ & 5.980 & 0.013 & 5.950 & 5.998 \\
\hline & & $t_{0}(\mathrm{mo})$ & -0.648 & 0.961 & -1.948 & 1.525 \\
\hline & & $\sigma_{t}^{2}$ & 0.004 & 0.004 & $1.732 \times 10^{-4}$ & $\begin{array}{l}40.015 \\
4\end{array}$ \\
\hline
\end{tabular}

\section{DISCUSSION}

The early life of juvenile mussels Epioblasma brevidens (from Day 1 to 2 mo) is a critical stage in the life cycle. The mussel culture methods used at FMCC have greatly improved the survival and growth of this endangered species (Hua et al. 2013). Rearing larger-sized (>20 mm) juvenile mussels for release is an important first step to restore imperiled populations. Mark-recapture techniques using PIT tags helps to ensure the success of evaluating mussel restoration efforts (Hua et al. 2015). Hence our study, covering the critical stages of juvenile propagation, culture, and release to monitoring provided a demonstration of conservation and restoration of an endangered mussel species.

The quantitative analyses directly influenced our understanding of mussel growth variation. Although the VBGM is perhaps the most commonly used growth model to characterize freshwater mussel length-at-age data (Hastie et al. 2000), this model needs to be evaluated on a case-by-case basis to avoid potential biases and erroneous parameter estima-

ent, with Model 3 having the lowest value of 1683.0, Model 1 the largest DIC value of 3292.8, followed by Model 2 with a DIC value of 2546.0. The difference in DIC units of Models 1 and 2 to Model 3 greatly exceeded 7 DIC units. Hence, Model 3 outperformed the other models and was determined to be the best model. Hierarchical Model 3, which considered the non-growth seasons and incorporated individual variations, optimally characterized growth of juvenile E. brevidens in the laboratory culture environment, and later when released to the river.

Water temperature and organic matter (represented by AFDW) were determined in this study from 28 October 2008 to 28 October 2009 (Table 2). The water temperature dramatically decreased at the end of October and rose at the end of April at the release site. Simultaneously, the AFDW declined about 3-fold during the low temperature period. These 2 parameters exhibited a very strong positive relationship (Pearson's $r=0.72$ ). The duration of low temperature and AFDW during an annual cycle occurred during the period of mussel growth cessation. tion. For instance, the traditional VBGM was applied in our study and resulted in a poor goodness-of-fit. Most of the observations (blue dots) were obviously

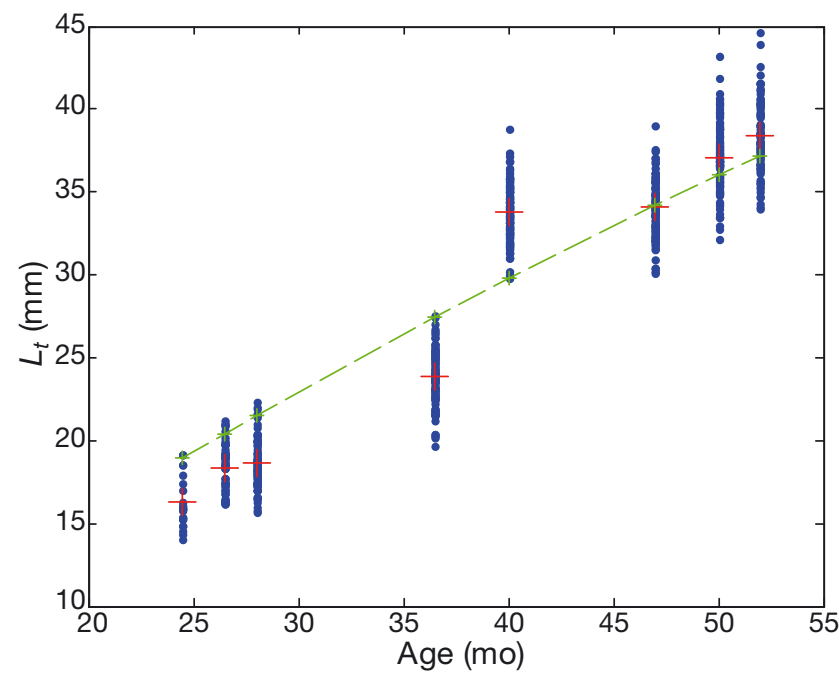

Fig. 5. Fits for Model 1 shown as green dashed line with estimated growth in length of released mussels of Epioblasma brevidens from 24.5 to 52 mo of age. $\bullet$ : observation of an individual mussel; + : mean mussel size at each observation 

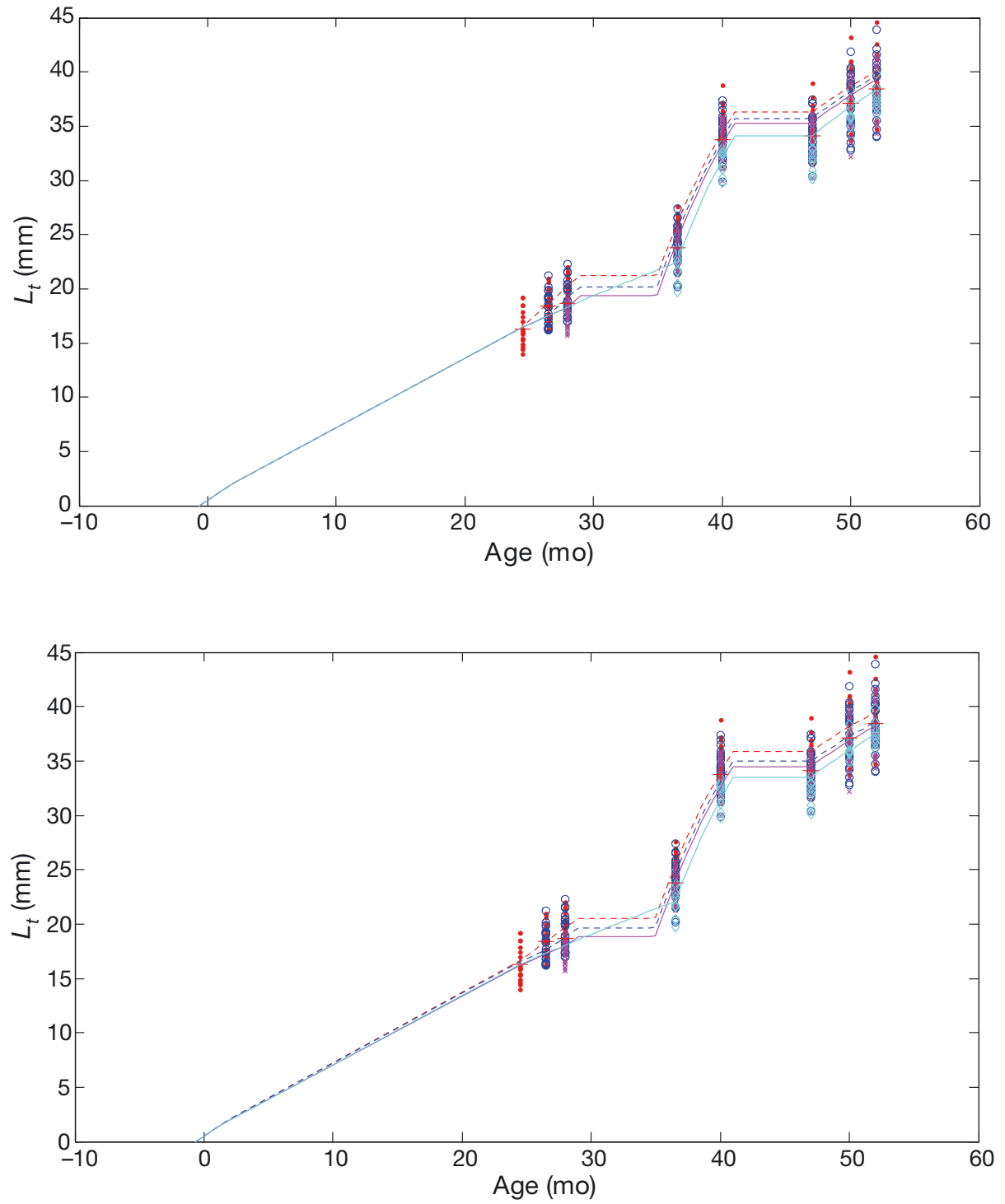

Fig. 6. Fits for Model 2 with estimated growth in length of juvenile mussels of Epioblasma brevidens from 0 to 52 mo of age (before and after release). Symbols: observed mussel sizes; lines: posterior model fit. Red filled circles and red dashed line: mussels released in July 2009; dark blue open circles and dark blue dashed line: mussels released in August 2009; maroon ' $x$ ' and line: mussels released in October 2009; light blue open diamonds and solid light blue line: mussels released in June 2010

Fig. 7. Fits for Model 3 with estimated growth in length of juvenile mussels of Epioblasma brevidens from 0 to 52 mo of age (before and after release). See Fig. 6 for a description of symbols and lines below the green dotted line (plot of VBGM growth curve) in Fig. 5, showing the overestimation. The estimated mean value of $L_{\infty}(99.18 \mathrm{~mm})$ in Model 1 exceeded those of Model 2 and Model 3 by about $46 \mathrm{~mm}$. Miguel et al. (2004) found that when the VBGM was applied to the youngest age classes $(<6 \mathrm{yr})$ of freshwater mussels, it underestimated the value of $L_{\infty}$. Poor fit of a model could be due to applying inappropriate models that are incapable of describing growth variation in individual animals.

In general, juvenile mussels grow rapidly during early life stages, peaking then decreasing in growth increments until achieving a near-constant size. Mussels also exhibit a seasonal growth pattern, with cessation caused by ambient environmental changes of low temperature, food restriction, minimal flow,
Table 2. Water temperature and organic matter values near the release site in Powell River, from October 2008 to October 2009. Organic matter content is indicated by ash free dry weight (AFDW)

\begin{tabular}{|lcc|}
\hline $\begin{array}{l}\text { Date } \\
(\mathrm{mm} / \mathrm{dd} / \mathrm{yy})\end{array}$ & $\begin{array}{c}\text { Water temperature } \\
\left({ }^{\circ} \mathrm{C}\right)\end{array}$ & $\begin{array}{c}\text { AFDW } \\
\left(\mu \mathrm{g} \mathrm{ml}^{-1}\right)\end{array}$ \\
\hline $10 / 28 / 08$ & 10.00 & - \\
$01 / 22 / 09$ & 1.20 & - \\
$02 / 24 / 09$ & 5.40 & - \\
$03 / 25 / 09$ & 12.70 & - \\
$04 / 29 / 09$ & 19.90 & 0.20 \\
$05 / 28 / 09$ & 21.40 & 0.73 \\
$06 / 25 / 09$ & 23.80 & 0.63 \\
$07 / 17 / 09$ & 24.00 & 0.93 \\
$08 / 27 / 09$ & 21.70 & 0.95 \\
$10 / 28 / 09$ & 13.30 & 0.23 \\
\hline
\end{tabular}


or inadequate energy storage for reproduction (Shul'man 1974, Adam 1990, Pauly et al. 1992, Downing \& Downing 1993, Miguel et al. 2004). Our results indicated that the duration of GC for E. brevidens in the Powell River lasted approximately 6 mo, beginning in late October to early November when water temperatures decreased below $15^{\circ} \mathrm{C}$, and ending in late April to early May when water temperatures increased above $15^{\circ} \mathrm{C}$. During the winter, GC occurred during the laboratory culture period and after mussels were released to the Powell River. Loss in shell length was detected during their GC periods in the river, although the reduced length of individuals was inconsequential. This result corroborates a previous study reporting negative growth due to resorption in winter (Downing \& Downing 1993). Regardless of GC or negative growth of mussels, we found that the duration of mussel GC correlated to the fluctuations in water temperature and food availability. Our determination of food availability was based on the AFDW of organic matter in sampled river water, which includes algae, bacteria, zooplankton, and other organic debris as suitable food (Silverman et al. 1997, Hua et al. 2013). The amount of AFDW declined to a low level from the end of October until the following May, while water temperatures declined to between 10 and $13^{\circ} \mathrm{C}$ at the end of October and remained lower until early April, then rose to $20^{\circ} \mathrm{C}$ in late April. Environmental changes directly influenced mussel growth, affecting GC and growth loss. However, Model 1 applied with the classic VBGM was not capable of simulating these seasonal growth patterns.

To determine seasonal growth patterns, a modified VBGM was applied by adding a sine wave with 2 more parameters to allow for seasonal oscillation (Pitcher \& MacDonald 1973):

and

$$
E\left(L_{t}\right)=L_{\infty}\left(1-\mathrm{e}^{-k_{s}}\right)
$$

$$
k_{s}=C \sin \left[\frac{2 \pi(t-s)}{12}\right]+k\left(t-t_{0}\right)
$$

where $k_{S}$ is the function that describes seasonal perturbation through a sine wave, $C$ donates the magnitude of the oscillations of sine wave, and $s$ represents the starting point in time relative to $t_{0}$. The other parameters, $L_{t}, L_{\infty}, t_{0}$, are defined as in Eqs. (2) \& (3), and the value 12 equals sampling occasions in months.

Although this seasonal growth model was verified and applied to our data, it was incapable of accommodating growth during GC, which was similar to that found in a previous study (Pauly et al. 1992). To solve this problem, Pauly et al. (1992) developed a better seasonal model by incorporating a no-growth time. We initially applied Pauly's improved mathematical function in our study, but it failed to simulate the growth pattern during the laboratory culture stage and post-release stage with multiple releases. Besides the above situation, the no-growth time in our study was much longer than the allowance of Pauly's model using the sine wave. Moreover, mussel growth exhibited obvious uneven oscillations that indicated different growth rates at various stages, which required the specification of different growth rates in the model to distinguish growth characteristics for each duration. Hence, 2 new models (Models 2 and 3) were developed to incorporate GC with a starting point of 1 November, associated with an upper boundary of 6 mo. According to the empirical data, we discarded the sine wave and generated 4 growth rates to fit the uneven oscillation growth pattern of $E$. brevidens. The estimated asymptotic length from Models 2 and 3 were 53.31 and 51.36 $\mathrm{mm}$, respectively, much less than the value $(99.18$ $\mathrm{mm}$ ) from Model 1. To investigate the reality of these results, we surveyed various museum collections to document the maximum length of E. brevidens collected from the Powell River, and found that the largest specimen was $71.9 \mathrm{~mm}$ (female) in the North Carolina State Museum of Natural Sciences, $62.4 \mathrm{~mm}$ (female) and $64.5 \mathrm{~mm}$ (male) in McClung Museum of Natural History and Culture, University of Tennessee, and $75 \mathrm{~mm}$ (female) in the Museum of Biological Diversity at Ohio State University. Parmalee \& Bogan (1998) reported the average length of mature specimens of $E$. brevidens to be around $50 \mathrm{~mm}$. Our results from Models 2 and 3 were seemingly plausible when compared to the museum records, because $L_{\infty}$ in this study was determined by laboratory-produced juveniles that experienced environmental changes in the early life stage.

It is known that growth parameters differ from species to species, but they also vary among individuals and among stocks within the same species, due to environmental responses and genetic differences. Our results indicated that growth rates differed at various stages, with the lowest $K_{1}$ in the culture period and highest $K_{3}$ at Age 3. Newly metamorphosed juvenile mussels experience environmental change after they excyst from host fish, which results in high mortality and slow growth. The second challenge to released juveniles is adaptation to the ambient environment and available food sources. Hence, $K_{2}$ did not exhibit rapid growth until acclima- 
tion and Age 3 yr. Thereafter, mussels became sexually mature and gravid females were observed during the recapture events at Age 4, which was $1 \mathrm{yr}$ earlier than predicted (Jones et al. 2012). The energy investment for reproduction influenced growth in length, resulting a smaller growth rate $\left(K_{4}\right)$ at this stage. The other life history trait, $t_{0}$, estimated from Models 2 and 3 were -0.649 and $-0.648 \mathrm{mo}$, which likely indicated the duration of glochidial metamorphosis from parasitic glochidium (larvae of mussel) to juvenile mussel. These $t_{0}$ values agreed with empirical data, namely that glochidia of $E$. brevidens encyst on host fish for 15 to $20 \mathrm{~d}$ before becoming free-living juveniles. However, the estimated value (1.94 mo) from Model 1 was not reasonable. Hence, the life history traits of E. brevidens in the Powell River at different stages are best interpreted through Models 2 and 3.

To better understand the characteristics of population biology and ecology, individual variation is an important component to be considered in quantitative analyses (Pledger et al. 2003, Jiao et al. 2009, 2010), though it is challenging and requires advanced computing techniques. We developed a hierarchical model (Model 3) with multi-level priors to incorporate individual variation using a Bayesian approach, along with MCMC algorithms. Although the estimated parameters of life history traits of $E$. brevidens were very close to those of Model 2, Model 3 significantly out-performed Model 2 according to the rules of thumb (Spiegelhalter et al. 2002), the criterion of model selection. Thus, Model 3 was determined to be the best model due to its smallest DIC value (1683.0). Our results also showed that small variances of $L_{\infty}$ and $K$ values in all models were probably due to the similarity of the same cohorts.

In a previous study, the growth parameters of $E$. brevidens from the Clinch River, Tennessee, were estimated using classic VBGM, based on annuli for age-at-length (Jones \& Neves 2011). However, using annular growth marks for delineating annual growth increments to estimate an age has been debated (Downing \& Downing 1993, Strayer et al. 2004). Excluding measurement error and shell erosion, Downing \& Downing (1993) reported negative growth in freshwater mussels, and indicated that growth rates based on annuli could be inaccurate since growth annuli were not reliable. Indeed, it is difficult to obtain lengths at defined ages of specimens from field records; hence, parameter estimation through use of annuli and corresponding lengths is still acceptable. We were able to produce juvenile mussels and release them at a precise age, thus re- solving the problem of age determination. Information of juvenile growth at these early life stages was invaluable. Our individual growth model allowed for individual variation, duration of $\mathrm{GC}$, and periodic growth rates $\left(K_{g}\right)$, along with multiple release events (different starting points) to provide a flexible model framework adapted to alternative data structures and mussel growth variation. For example, it can be applied to growth patterns without GC by setting the $\mathrm{GC}=0$. The improvement of mark-recapture methodology using PIT technology greatly increased recapture rates and effectively reduced the uncertainties in parameter estimation.

It is important to have complete information for all age classes to determine the growth parameters of a species' lifespan (Haag 2009). Therefore with additional study, we can refine the results of our current estimation for this endangered species by incorporating middle and old age classes in the analytical modeling. Despite the advantage of this mark-recapture method, a bias derived from mussel handling was observed by Haag (2009). This can be resolved using unsampled mussels as controls in future studies.

Acknowledgements. The authors thank the staff and students at FMCC for their assistance in propagation, culture, release, and recapture of juvenile mussels. The grant and facility support for this work was provided by the US Fish and Wildlife Service, US Geological Survey, and Department of Fish and Wildlife Conservation at Virginia Polytechnic Institute and State University. Thanks to Steven Ahlstedt, Arthur Bogan, Clarissa Bey, Gerald Dinkins, and George Watters for sharing their data. The views expressed in this article are those of the authors and do not necessarily represent those of the US Fish and Wildlife Service. The authors are solely responsible for the content of the materials, methodology, and results. Queries should be directed to the corresponding author.

\section{LITERATURE CITED}

Adam ME (1990) Shell growth in some Nile bivalves. J Molluscan Stud 56:301-308

Ahlstedt SA, Fagg MT, Butler RS, Connell JF (2005) Longterm trend information for freshwater mussel populations at twelve fixed-station monitoring sites in the Clinch and Powell rivers of eastern Tennessee and southwestern Virginia, 1979-2004. Final Report, US Fish and Wildlife Service, Cookeville, TN

Alanara A, Burns D, Metcalfe NB (2001) Intra-specific resource partitioning in brown trout: the temporal distribution of foraging is determined by social rank. J Anim Ecol 70:980-986

Allison EH (1994) Seasonal growth models for great scallops (Pecten maximus (L.)) and queen scallops (Aequipecten opercularis (L.)). J Shellfish Res 13:555-564

Alós J, Palmer M, Balle S, Grau AM, Morales-Nin B (2010) Individual growth pattern and variability in Serranus 
Scriba: a Bayesian analysis. ICES J Mar Sci 67:502-512

Anthony JL, Kesler DH, Downing WL, Downing JA (2001) Length-specific growth rates in freshwater mussels (Bivalvia: Unionidae): Extreme longevity or generalized growth cessation? Freshw Biol 46:1349-1359

APHA (American Public Health Association) (1998) Standard methods for the examination of water and wastewater. APHA, Washington, DC

* Bacon PJ, Gurney WSC, Jones W, McLaren IS, Youngson AF (2005) Seasonal growth patterns of wild juvenile fish: partitioning variation among explanatory variables, based on individual growth trajectories of Atlantic salmon (Salmo salar) parr. J Anim Ecol 74:1-11

Cam E, Link WA, Cooch EG, Monnat JY, Danchin E (2002) Individual covariation between life-history traits: seeing the trees despite the forest. Am Nat 159:96-105

* Cloern JE, Nichols FH (1978) A von Bertalanffy growth model with a seasonally varying coefficient. J Fish Res Board Can 35:1479-1482

Conner MM, White GC (1999) Effects of individual heterogeneity in estimating the persistence of small populations. Nat Resour Model 12:109-127

* Cope W, Waller D (1995) Evaluation of freshwater mussel relocation as a conservation and management strategy. Regul Rivers Res Manage 11:147-155

Downing WL, Downing JA (1993) Molluscan shell growth and loss. Nature 362:506

* Downing WL, Shostell J, Downing JA (1992) Non-annual external annuli in the freshwater mussels Anodonta grandis grandis and Lampsilis radiata siliquoidea. Freshw Biol 28:309-317

Fabens AJ (1965) Properties and fitting of the von Bertalanffy growth curve. Growth 29:265-289

* Gimenez O (2008) Discussion: Towards a Bayesian analysis template? Can J Stat 36:21-24

* Graf DL (2013) Patterns of freshwater bivalve global diversity and the state of phylogenetic studies on the Unionoida, Sphaeriidae, and Cyearenidae. Am Malacol Bull 31:135-153

Haag WR (2009) Extreme longevity in freshwater mussels revisited: sources of bias in age estimates derived from mark-recapture experiments. Freshw Biol 54:1474-1486

Haag WR (2012) North American freshwater mussels: natural history, ecology, and conservation. Cambridge University Press, New York, NY

HHaag WR, Rypel AL (2011) Growth and longevity in freshwater mussels: evolutionary and conservation implications. Biol Rev Camb Philos Soc 86:225-247

Haag WR, Williams JD (2014) Biodiversity on the brink: an assessment of conservation strategies for North American freshwater mussels. Hydrobiologia 735:45-60

Haddon M (2001) Modelling and quantitative methods in fisheries. CRC Press, Boca Raton, FL

Hamilton H, Box JB, Dorazio RM (1997) Effects of habitat suitability on the survival of relocated freshwater mussels. Regul Rivers Res Manage 13:537-541

Hastie CC, Young MR, Boon PJ (2000) Growth characteristics of freshwater pearl mussels, Margaritifera margaritiera (L.). Freshw Biol 43:243-256

Hilborn R, Walters CJ (1992) Quantitative fisheries stock assessment (choice, dynamics, and uncertainty). Chapman \& Hall, New York, NY

Hoenig NA, Hanumara RC (1990) An empirical comparison of seasonal growth models. Fishbyte 8:32-34

*Hua D, Neves RJ, Jiao Y (2013) Effects of algal density, water flow and substrate type on culturing juveniles of the rainbow mussel (Villosa iris) (Bivalvia: Unionidae) in a laboratory recirculating system. Aquaculture 416-417: 367-373

KHua D, Jiao Y, Neves RJ, Jones J (2015) Using PIT tags to assess individual heterogeneity in a mark-recapture study of laboratory-reared juveniles of the endangered Cumberlandian combshell (Epioblasma brevidens). Ecol Evol 5:1076-1087

James IR (1991) Estimation of von Bertalanffy growth curve parameters from recapture data. Biometrics 47: 1519-1530

Jiao Y, Neves RJ, Jones JW (2008) Models and model selection uncertainty in estimating growth rates of endangered freshwater mussel populations. Can J Fish Aquat Sci 65:2389-2398

Jiao Y, Reid K, Smith E (2009) Model selection uncertainty and Bayesian model averaging in fisheries recruitment modeling. In: Beamish RJ, Rothschild BJ (eds) The future of fisheries science in North America. Springer, Berlin, p 505-524

* Jiao Y, Rogers-Bennett L, Taniguchi I, Butler J, Crone P (2010) Incorporating temporal variation in the growth of red abalone (Haliotis rufescens) using hierarchical Bayesian growth models. Can J Fish Aquat Sci 67: 730-742

Johnson MS (2011) A quantitative survey of the freshwater mussel fauna in the Powell River of Virginia and Tennessee, and life history study of two endangered species, Quadrula sparsa and Quadrula intermedia. MSc thesis, Virginia Polytechnic Institute and State University, Blacksburg, VA

Jones JW, Neves RJ (2011) Influence of life-history variation on demographic responses of three freshwater mussel species (Bivalvia: Unionidae) in the Clinch River, USA. Aquat Conserv: Mar Freshw Ecosyst 21:57-73

Jones JW, Neves RJ, Hallerman EM (2012) Population performance criteria to evaluate reintroduction and recovery of two endangered mussel species, Epioblasma brevidens and Epioblasma capsaeformis (Bivalvia: Unionidae). Walkerana: J Fresh Moll Con Soc 35:27-44

KKimura DK (2008) Extending the von Bertalanffy growth model using explanatory variables. Can J Fish Aquat Sci 65:1879-1891

Krohn MM, Reidy SP, Kerr SR (1997) Bioenergetic analysis of the effects of temperature and prey availability on growth and condition of northern cod (Gadus morhua). Can J Fish Aquat Sci 54:113-121

Miguel ES, Monserrat S, Fernández C, Amaro R, Hermida M, Ondina P, Altaba CR (2004) Growth models and longevity of freshwater pearl mussels (Margaritifera margaritifera) in Spain. Can J Zool 82:1370-1379

National Native Mussel Conservation Committee (1998) National strategy for the conservation of freshwater mussels. J Shellfish Res 17:1419-1428

Neves RJ (2008) Restoring endangered mussels. Endang Species Bull 33:54-56

Neves RJ, Moyer SN (1988) Evaluation of techniques for age determination of freshwater mussels (Unionidae). Am Malacol Bull 6:179-188

Parmalee PW, Bogan AE (1998) The freshwater mussels of Tennessee. University of Tennessee Press, Knoxville, TN

Pauly D, Gaschultz G (1979) A simple method for fitting oscillating length growth data, with a program for pocket calculators. ICES CM 1979/G24. www.seaaroundus.org/ 
doc/Researcher+Publications/dpauly/PDF/1979/Other/ OscillatingLengthData.pdf

Pauly D, Soriano-Bartz M, Moreau J, Jarre-Teichmann A (1992) A new model accounting for seasonal cessation of growth in fishes. Aust J Mar Freshw Res 43:1151-1156

Pitcher TJ, MacDonald PDM (1973) Two models for seasonal growth in fishes. J Appl Ecol 10:599-606

Pledger S, Pollock KH, Norris JL (2003) Open capturerecapture models with heterogeneity: I. Cormack-JollySeber model. Biometrics 59:786-794

Ricciardi A, Rasmussen JB (1999) Extinction rates of North American freshwater fauna. Conserv Biol 13:1220-1222

Rizvi AF, Amitabh CD, Singh KP (2012) Growth pattern of Labeo calbasu (Ham) affected by socio-geographical condition of the riverine habitat. Curr Res J Biol Sci 4: 250-257

Shul'man GE (1974) Life cycles of fish: physiology and biochemistry. Wiley \& Sons, New York, NY

Silverman H, Nichols SJ, Cherry JS, Achberger E, Lynn JW, Dietz TH (1997) Clearance of laboratory-cultured bacteria by freshwater bivalves: differences between lentic and lotic unionids. Can J Zool 75:1857-1866

Smith EB, Williams FM, Fisher CR (1997) Effects of intrapopulation variability on von Bertalanffy growth parameter estimates from equal mark-recapture intervals. Can J Fish Aquat Sci 54:2025-2032

Somers IF (1988) On a seasonally oscillating growth function. Fishbyte 6:8-11

Spiegelhalter DJ, Best NG, Gilks WR, Inskip H (1996) Hepatitis B: a case study in MCMC methods. In: Gilks WR, Richardson S, Spiegelhalter DJ (eds) Markov chain Monte Carlo in practice. Chapman \& Hall, London, p 21-43

Editorial responsibility: David Lusseau, Aberdeen, UK
Spiegelhalter DJ, Best NG, Carlin BP, Linde AVD (2002) Bayesian measures of model complexity and fit. J R Stat Soc B 64:583-639

Spiegelhalter DJ, Thomas A, Best NG, Lunn D (2004) WinBUGS user manual (version 1.4.1). Medical Research Council Biostatistics Unit, Cambridge

* Strayer DL, Downing JA, Haag WR, King TL, Layzer JB, Newton TJ, Nichols SJ (2004) Changing perspectives on pearly mussels, America's most imperiled animals. Bioscience 54:429-439

Swain DP, Sinclair AF, Castonguay M, Chouinard G, Drinkwater KF, Fanning L, Clark DS (2003) Densityversus temperature-dependent growth of Atlantic cod (Gadus morhua) in the Gulf of St. Lawrence and on the Scotian Shelf. Fish Res 59:327-341

Tang M, Jiao Y, Jones J (2014) A hierarchical Bayesian approach for estimating freshwater mussel growth based on tag-recapture data. Fish Res 149:24-32

Ursin E (1963) On the incorporation of temperature in the von Bertalanffy growth equation. Medd Dan Fisk Havunders N S 4:1-16

USFWS (2004) Recovery plan for Cumberland elktoe, oyster mussel, Cumberlandian combshell purple bean, and rough rabbitsfoot. US Fish \& Wildlife Service, Atlanta, GA

von Bertalanffy L (1938) A quantitative theory of organic growth (inquiries on growth laws. II). Hum Biol 10: 181-213

Wade PR (2000) Bayesian methods in conservation biology. Conserv Biol 14:1308-1316

Williams JD, Warren ML Jr, Cummings KS, Harris JL, Neves RJ (1993) Conservation status of freshwater mussels of the United States and Canada. Fisheries 18:6-22

Submitted: April 6, 2016; Accepted: September 15, 2016 Proofs received from author(s): November 16, 2016 